\title{
Взаимосвязь рукописных тефсиров и китабов митовских татар: коранический аят 36:14 и «Посольство Исы в Антиохию» **
}

DOI: http://dx.doi.org/10.12775/LC.2020.004

\begin{abstract}
Аннотация: В статье рассматривается взаимодействие Авух книжных жанров славяноязычной арабскоалфавитной письменности татар Великого княжества Аитовского: тефсиров (содержащих экзегетический перевод Корана) и китабов (сборников мусульманских религиозных рассказов). На примере коранического аята 36:14 показана взаимосвязь польского перевода Корана, записанного арабским письмом в тефсирах (рукописи XVII-XX вв.), с одним из списков тематически близкого китабного текста «Посольство Исы в Антиохию». Аанный аят упоминает трех безымянных посланников, которые в мусульманской традиции обычно считаются Иоанном, Иудой и Симоном-Петром, апостолами Иисуса (Исы). При этом польский тефсирный перевод называет их Яном, Стефаном и Симеоном (т.е. Симоном), а китабный текст Яхьей, Шевбаном и Шемуном. Рассмотрение Авуименности китовских татар, соотносивших свои мусульманские имена с христианскими, позволяет преАполагать здесь единую экзегетическую традицию, предполагавшую взаимное соотнесение парных форм Ян и Яхья, Стефан и Шевбан, Семеон и Шемун. Это подтвержАает также маргинальная глосса, переписанная из тефсира в китаб.
\end{abstract}

Ключевые слова: митовские татары, китабистика, Коран, тефсир, китаб

\footnotetext{
* Сергей Юрьевич Темчин

Профессор Института литовского языка (Вильнюс), научные интересы: палеославистика, в том числе славянская литература Великого княжества Литовского.

E-mail: sergejus.temcinas@flf.vu.It | ORCID: 0000-0002-6706-5963.

** Данная работа выполнена в рамках исследовательского проекта, поддержанного Национальной программой развития гуманитарных наук Польши (Narodowy Program Rozwoju Humanistyki Ministerstwa Nauki i Szkolnictwa Wyższego, 11 H 16031984; 2017-2021).
} 


\title{
Interrelation between Lithuanian Tatars' Manuscript Tafsirs and Kitabs: Ayah 36:14 and "Jesus' mission to Antioch"
}

\begin{abstract}
The article discusses one case of interrelation between the Polish translation of the Quran written using the Arabic script in the tefsirs by Tatars of the Grand Duchy of Lithuania and their manuscript kitabs. The focus is placed on ayah 36:14 in its relation to the narrative "Jesus' mission to Antioch" (according to the British Library Kitab OR 13020 of the mid-19 ${ }^{\text {th }} \mathrm{c}$.). While the three nameless messengers of the ayah are usually believed to be Jesus' disciples John, Judah, and SimonPeter who were sent to Antioch, the Polish tefsir translation names them John, Stephen, and Simon. The author argues that these are merely Christian forms of the Muslim names „Jechja“, „Ševban“, and „Šeme 'un" presented in the same context in the kitab narrative "Jesus' mission to Antioch". On the other hand, the above mentioned copy of the latter text contains two marginal notes (to ayah 36:14) which cite the Christian forms of the names derived from the Polish manuscript tefsir. A preliminary list of correspondences between Muslim and Christian names used by Lithuanian Tatars is also given in the article.
\end{abstract}

Keywords: Lithuanian Tatars, kitabistics, Qur’an, Tefsir, Kitab

ольский перевоА Корана, содержащийся в арабскоалфавитных рукописных тефсирах татар Великого княжества Аитовского (Аалее - ВКА), выполнен с арабского и/или тюркского языка и представцен относительно позАними списками, наиболее ранние из которых датируются концом XVII века ${ }^{1}$.

Время и место выполнения этого перевода доподлинно неизвестны. Его возникновение Аатируется по-разному в промежутке от первой половины XVI века Ао начала мибо второй половины XVII века². Перевод приписывается минскому имаму Урьяшу ибн Исмаилу, названному переводчиком в колофоне наиболее раннего тефсиpa 1686 года ${ }^{3}$. Но поскольку слово «переводчик» может означать род Аеятельности чемовека вообще, безотносительно к конкретному тексту, то не вполне понятно, быц ми Урьяш автором Аанного перевода или же просто переписчиком самого раннего списка тефсира из числа сохранившихся. Известно также, что Петр Старковецкий († после 1644 г.), переводчик турецкого языка (владевший также персидским и арабским) королевской канцелярии Владислава IV, перевел Коран (вероятно, не с арабского оригинала, а с османского перевода) на польский язык, но не успел опубликовать свой перевоА, рукопись которого, скорее всего, пропала. Поскольку в арабскоалфавитные рукописи татар ВКА нередко арабскими буквами переписывамись христианские по происхождению тексты на польском языке, то следует считаться с теоретической воз-

\footnotetext{
1 Этому переводу посвящены издания: (Suter 2004; Suter 2009; Kulwicka-Kamińska et al. 2015).

2 Подробнее с литературой вопроса см.: (Temczyn 2015: 213-214).

3 См. публикацию и обсуждение колофона (Tarełka 2006).
} 
можностью как мусульманско-татарского, так и христианско-польского происхождения интересующего нас тефсирного перевода Корана ${ }^{4}$.

Сейчас уже можно указать по крайней мере четыре аргумента в пользу мусульманского (а не христианского) происхождения рассматриваемого польского перевода Корана, который:

1) содержит в себе непереведенные арабизмы и иные ориентализмы (в том числе терминологического характера), которые вряА ми могли быть оставлены в тексте христианским переводчиком;

2) Аополнен краткими экзегетическими вставками, актуальными прежде всего Амя мусульманской аудитории, причем ввиду их значительного количества маловероятно, что такие текстовые добавления могли быть внесены в перевод Корана вторично;

3) в значительной степени основан на арабском источнике (Танвир аль-микбас мин тафсир Ибн Аббас) (Теmсzуn 2016: 95-119).

4) зависит от внекоранической (хотя и связанной с толкованием Корана) рукописной традиции митовских татар.

Обоснованию последнего положения и посвящена настоящая статья.

Ранее было показано, что польский перевод Корана, сохранившийся в рукописных тефсирах, был положен в основу более позднего тефсира-комментария (он известен мишь Аля сур 78-114) (Synkowa 2016: 151-160).

Ниже на примере 14-го аята 36-й суры (Йа Син) я постараюсь показать взаимосвязь польского рукописного перевоАа Корана, преАставленного в тефсирах татар ВКА, с иным типом бытовавших у них книг, а именно - с китабами. Поскольку этот содержащийся в тефсирах коранический перевод содержит краткие (часто состоящие из одного слова) дополнения экзегетического характера, то я буду называть его тефсирным, т.е. толковательным, комментирующим, интерпретирующим (по аналогии с таргумическими переводами иудейской традиции). С одной стороны, такие экзегетические Аополнения, присутствующие в польском переводе Корана, вероятно, основаны на содержащихся в китабах текстах или по крайней мере содержательно согласованы с ними. С Аругой стороны, некоторые списки китабов, наоборот, обнаруживают вторичное влияние со стороны польского тефсирного перевода Корана.

Проследим эту взаимосвязь на примере коранического аята 36:14 (Вот послали Мы к ним Авоих, и они сочли их мжецами; Мы усилили третьим, и они сказали: «Мы ведь к вам посланные $)^{5}$.

В польском тефсирном переводе он имеет следующий виА (Аается в современной польской орфографии; экзегетические добавления выделены):

*W ten czas posłaliśmy do nich dwóch, jednemu imię Jan i Stefan [в одном позАнейшем списке: Mustafa], przeto okłamali ich, i poświęciliśmy tych, abo podparli trzecim, Szymonem [в некоторых списках глосса: Szym on jest Piotr], przeto ci rzekli: pewnie my do was posły jesteśmy $y^{6}$.

\footnotetext{
4 Подробнее см. Temczyn 2015: 213-242.

5 Перевод цитируется по изданию: Kraczkowskij 1990: 360.

6 Цитируется (с дополнительной информацией) по публикации реконструированного польского перевода 36-й суры (Йа Син): Temсzyn 2016: 98.
} 
Безымянное селение, куда были отправлены послы, современные комментаторы Корана обычно считают Антиохией ${ }^{7}$, а самих посланников - апостолами Иисуса (пророка Исы ибн Марьям в исламской традиции): первых двух - Иоанном и Иудой, а третьего - Симоном-Петром, хотя ранняя экзегеза характеризуется разнобоем мнений, ср. освещение вопроса Абу Исхаком ас-Салаби (ум. в 1035 г.):

There were differences of opinion about the names of these two messengers. According to Ibn Ishạā, they were Fārūụ and Rūmāọ, but Wahb said: Yahỵā (John) and Yūnus (Jonah). Muqātil said Yūmān and Mālūs, while Kacb said Șādiq and Șudūq. „[they called them liars; so We sent a third to strengthen them.]". (36:13-14) - that means that we strengthened them with a third messenger, namely Simon the Brass-worker, the leader of the Disciples according to most of the commentators. However $\mathrm{Ka}^{\mathrm{c}} \mathrm{b}$ said that his name was Shalūm, but Muqātil said that it was Samª̄n (Brinner 2002: 676).

Нетрудно заметить, что в основе наиболее распространенного сейчас толкования межит версия, автор которой - Вахб ибн Мунаббих (654/5-728 или 732 г. н.э.), знаток иудейской и христианской традиций: мишь вместо первоначального имени Иона теперь принимается Иуда.

Как видим, в польскоязычном переводе Корана имя второго посланника (Стефан) значительно отличается от обычно предполагаемого (Иуда). Аюбопытно, что весьма схожий набор имен встречается в белорусскоязычном тексте «Посольство Исы в Антиохию», нередко содержащемся в китабах и объясняющем коранические аяты 36:13-35. Он опубликован в польском переводе по Китабу Милькамановича 1782/83 г. (частное собрание) (Jankowski et al. 2000: 119-127) и в катинской тран-

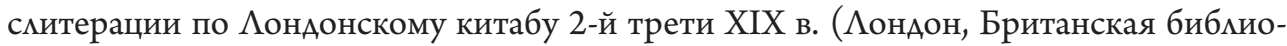
тека, OR 13020, ^. 11a-146) (Akiner 2009: 369-382). Ниже пользуюсь последним из указанных изАаний.

В этом тексте, в частности, сообщается:

kali 'Is̀a prorok pačav ludźej da veri pravdźivaj navaračac pa mestach razeslav svajich tovarišav, dvuch paslav da Antakiji mesta, adnaho zvane Jechja a druhij Ševban $<\ldots$.. Potim 'I’̀a prorok ješče jednego poslal do nich, na ime Šeme un (ibid.: 370-371).

При этом на помях возме Аанного текста имеется запись: Jak 'Isa trech poslov poslal do Antaḱiji jedin Jan, drugi Stafan (between lines 4-9); S̀eme'un jest Potr (between lines 23-24) (ibid.: 371).

Несомненно, что эти маргинальные приписки восходят к тефсирному переводу Корана. Первая запись основана на польском переводе аята 36:14 (W ten czas posłaliśmy do nich dwóch, jednemu imię Jan i Stefan [...] podparli trzecim, Szymonem). Вторая в точности воспроизводит Аругую глоссу к тому же аяту, содержащуюся в списках того же тефсирного перевода: в большинстве случаев она выписывается на полях, изредка - уже в самом тексте. Таким образом, здесь несомненно влияние тефсирного перевода Корана на конкретный текст китаба, проявившееся в маргиналиях послеАнего.

\footnotetext{
7 См., например: Nasr 2015: 1073.
} 
Приводя польские формы имен, автор приписок поставия их тем самым в соответствие восточным именам основного текста: Jechja - Jan; Ševban - Stafan; Šeme‘ un S̀eme 'un (он же Potr). Первая пара содержит разные варианты древнееврейского по происхожАению имени Йоханан, третья - весьма близкие версии Аревнееврейского имени Шимон, тогАа как центральная пара имен заслуживает особого комментария.

Севбан/Шевбан было известно среди татар Великого княжества Аитовского в форме Шабан ${ }^{8}$, от которой происходят митовские фамилии Шабанас, Шабанаускас, Шабаняускас 9 . Оно не восходит к имени греческого происхождения Стефан, тем не менее, по всей видимости, у татар ВКА эти имена взаимно соотносились. Аействительно, если бы автор приписок считал заимствованные из тефсирного перевода имена не синонимичными, а ацьтернативными тем, что приведены в основном тексте китаба, то он, скорее всего, тем или иным способом отметил бы наличие разногласий.

Известно, что митовские татары нереАко использовали Аве формы имени: мусульманскую (арабского или тюркского происхождения) и христианскую (могла употребляться как в польском, так и в восточнославянском облике), которые при этом не всегда были этимологически взаимосвязанными. Так, свод биографий известных литовских татар (Dumin et al. 2012) содержит такие статьи: Ассанович Александр Матвеевич (Ахметьевич), Кричинский Семен (Сулейман) Бимялович, Кумьзиманович Алей (Олей), он же Илья, АебеАзь Степан (Мустафа) Александрович, Мухля Мустафа (Степан) Абутелебович, Полторжицкий Иосиф Сулейманович (Семенович), Якубовский Александр Константинович (Хасеневич), Якубовский Венедикт Степанович (Мустафович), Якубовский Иосиф (Юзеф) Степанович (Мустафович), Якубовский Константин Степанович (Хасень Мустафович), Якубовский Константин (Хасень) Яковлевич, Якубовсий ФуаА Борисович (Бекирович), Якубовский Якуб Яхьич (Иванович), Янович-Чаинский Салих Мустафович (Сильвестр Степанович), Янушевский Ипполит (Халиль) Алексанарович.

Кроме того, в справочнике упоминаются также: Александр (Искандер), Константин (Керим), Али (Александр), Халифа (Елизавета), Мустафа (Остафий), Асия (Айша), Магмет (Матфей), Юсуф (Иосиф) Алиевич (Александрович), Александр (Алей), Мустафа (Стефан), Зана (Зося), Ян (Янбек, Ембек), Яхъя (Яхно) (Dumin et al. 2012: 241-242, 246, 251, 286, 314-317, 322, 326, 374).

Этот материал позволяет составить преАварительный список подобных соответствий мусульманских и христианских имен:

мужские

Али/Алей/Олей - Александр и Илья

Ахмет - Матвей

Бекир - Борис

Искандер - Александр

Керим - Константин

Магмет - Матфей

$$
\begin{aligned}
& \quad \text { женские } \\
& \text { Айша - Асия } \\
& \text { Зана - Зося } \\
& \text { Хацифа - Елизавета }
\end{aligned}
$$

8 Его носители: Шабан Барановский Туган (1661 г.) и, очевидно, Банько (уменьшительная форма от Шабан; 1522-1527 гг.), см.: Dumin et al. (2012: 251, 281).

9 Ср. иное объяснение: Vanagas (1989: 871). 
Мустафа - Степан/Стефан и Остафий

Салих - Симьвестр

Сумейман - Семен

Халиль - Ипполит

Хасень - Константин

Юсуф - Иосиф

Янбек/Ембек - Ян

Яхья - Иван/Ян и Яхно

Этот список показывает не только отсутствие обязательной этимологической связи межАу парными именами, но и неоднозначность именных соответствий, когАа оАно мусульманское имя соответствует нескольким христианским (Али/Алей/Олей Александр и Илья; Мустафа - Степан/Стефан и Остафий; Яхья - Иван/Ян и Яхно), а христианское - разным мусульманским (АлексанАр - Али/Алей/Олей и Искандер; Матфей/Матвей - Ахмет и Магмет; Константин - Керим и Хасень $)^{10}$.

В свете сказанного преАставцяется вполне вероятным, что тефсир 1843 г., писанный Яном Полтужицким, и тефсир 1846 г., писанный Яхьей Полтожицким (НовогруАок), принадлежат одному и тому же переписчику, пользовавшемуся как мусульманской, так и христианской формой своего имени (Drozd 2004: 240).

Таким образом, экзегетические дополнения в составе рассматриваемого тефсирного перевода аята 36:14, вероятно, восходят к китабному повествованию о посольстве пророка Исы в Антиохию: упомянутые в китабе имена Яхья, Шевбан и Шемун, повидимому, были внесены в польский перевод Корана в христианизированных формах Ян, Стефан и Симеон (что вполне естественно, ведь речь идет о христианах - посланниках Иисуса $)^{11}$, откуда эти новые формы вернулись в тот же текст китаба (по Аондонскому списку) в виде маргинальных записей, основанных на соответствующем тексте тефсира.

Аействительно, этимологическое тожАество форм внутри пар Яхья и Ян, Шемун и Симеон несомненно: за разными формами имен в этих парах наверняка стоят те же самые Аица. Взаимная соотнесенность у митовских татар этимологически неродственных, но фонетически более ими менее схожих мусульманских и христианских имен (типа Ахмет - Матвей; Бекир - Борис; Керим - Константин и т.А.) позвомяет предпомагать, что этимологически не связанные Аруг с Аругом имена Шевбан и Стефан также явцяются взаимосоотнесенными, т.е. преАполагают не Ава разных исторических или мегендарных мица, а одно (синонимичны на референтном уровне).

Аоказать это строгим образом невозможно, но тем не менее взаимная соотнесенность имен Шевбан и Стефан вполне вероятна. Во-первых, первое из них заведомо восточного происхожАения, а второе (восходящее в конечном счете к греческому) распространено в местном христианском ономастиконе. Во-вторых, фонетически они довольно близки - никак не в меньшей степени, чем в реально засвидетельствованных парах взаимно соотнесенных имен типа Магмет - Матфей. В-третьих, наличие

10 Подробнее и на более обширном материале см.: Dumin 2018: 222-224.

11 Некоторые исследователи даже считали эти христианизированные формы имен более привычными для литовских татар, см.: Meredith-Owens et al. 1970: 163. 
у греческого по происхождению имени Стефан/Степан иной реально зафиксированной пары (с именем Мустафа) не может свидетельствовать против предполагаемой парности имен Шевбан и Стефан, поскольку, как мы видели, как восточные, так и европейские формы имен митовских татар могут образовывать более одной пары даже на синхронном уровне, не говоря уже об историческом. По той же причине не явмяется препятствием и наличие иного христианского соответствия у митовско-татарского имени Шабан $(\rightarrow \text { Себастьян })^{12}$. В-четвертых, отсутствие специального комментария переписчика, перенесшего глоссы с именами посланников из тефсирного перевода аята 36:14 в китабную статью «Посольство Исы в Антиохию» также свидетельствует скорее за постулируемую пару Шевбан и Стефан, чем против нее (хотя силу аргумента ex silentio не стоит переоценивать).

B-пятых, принятие Аанного предположения способно объяснить замену имени Стефан $\rightarrow$ Мустафа в позднем списке тефсирного перевода (Хамаил Казанского университета середины XIX века-1844 г. с сигнатурой 3246 ap. $)^{13}$ : из-за неоднозначности мусульманско-христианских соответствий имен в Аитовско-татарской традиции восточное имя Шевбан (в китабе), видимо, сначаца было заменено на местное Стефан (в тефсире), но в указанном позднем списке было замещено иным восточным именем Мустафа - уже по иному соответствию, надежно засвидетельствованному у литовских татар (см. выше). Вся цепочка замен Шевбан $\rightarrow$ Стефан $\rightarrow$ Мустафа имеет культурноязыковой характер и не отражает смены экзегетических традиций: на первом шаге (Шевбан $\rightarrow$ Стефан) предположительно, на втором (Стефан $\rightarrow$ Мустафа) наверняка.

Более того, если второй этап (Стефан $\rightarrow$ Мустафа) надежно документирует опору писца на традицию Авуименности литовских татар (подтвержденную именами реальных членов этой общины), то Аанная типологическая парамлель повышает вероятность подобного же поведения иного книжника (более раннего времени), аАаптировавшего содержание китабной статьи «Посольство Исы в Антиохию» Аля польского тефсирного перевода Корана путем замены имен Шевбан $\rightarrow$ Стефан.

Предполагаемая зависимость рассматриваемого перевода Корана от внекоранической книжности татар Великого княжества Аитовского служит дополнительным (четвертым) аргументом в пользу татарско-мусульманского (а не польско-христианского) происхождения тефсирного перевода Корана на польский язык.

\section{Библиография}

Akiner, Shirin 2009. Religious Language of a Belarusian Tatar Kitab: A Cultural Monument of Islam in Europe with a Latin-Script Transliteration of the British Library Tatar Belarusian Kitab (OR 13020) on CD-ROM. Wiesbaden: Harrassowitz Verlag.

Brinner, William M. (tłum.) 2002. 'Arā'is al-majälis fì qișaṣ al-anbiyā', or "Lives of the prophets" as recounted by Abū Isḥāq Aḥmad ibn Muhammad ibn Ibrāhīm al-Thaclabī. Leiden-Boston- Köln: Brill.

\footnotetext{
12 Без указания на конкретный источник: Dumin 2018: 223.

13 Подробное описание рукописи: Miškinienè 2007: 264-278.
} 
Drozd, Andrzej 2004. „Koran staropolski. Rozważania w związku z odkryciem tefsiru mińskiego z 1686 roku”. Rocznik Biblioteki Narodowej 36: 237-250.

Dumin, Stanisław 2018. „Antroponimika litowskich tatar”. W: Joanna Kulwicka-Kamińska [\&] Czesław Łapicz [\&] Galina Miškinienè (red.). Tatarskie dziedzictwo kulturowe: Historia. Literatura. Sztuka. Toruń: Wydawnictwo Adam Marszałek.

Dumin, Stanisław [\&] Galim Sitdykow [\&] Adas Jakubauskas 2012. Litowskije tatary w istorii i kulturie. Wydanie drugie, poprawione i uzupełnione. Kowno: Sojuz obszczin tatar Litwy.

Jankowski, Henryk [\&] Czesław Łapicz 2000. Klucz do raju. Ksiega Tatarów litewsko-polskich $z$ XVIII wieku. Warszawa: Wydawnictwo Akademickie Dialog.

Kraczkowskij, Ignatij Julijanowicz (tłum.) 1990. Koran. Moskwa: Dom Biruni.

Kulwicka-Kamińska, Joanna [\&] Czesław Łapicz (red.) 2015. Tefsir tatarów Wielkiego Księstwa Litewskiego: teoria i praktyka badawcza. Toruń: Wydział Filologiczny Uniwersytetu Mikołaja Kopernika.

Meredith-Owens, Glyn Munro [\&] Alexander Nadson 1970. „The Byelorussian Tatars and their writings". Journal of Byelorussian Studies 2, 2: 141-176.

Miškinienè, Galina 2007. „Po sledam Kazanskogo kitaba KU-1446”. Senoji Lietuvos literatūra 24: $263-285$.

Nasr, Seyyed Hossein (ed.) 2015. The Study Quran: A New Translation with Notes and Commentary. San Francisco: HarperOne.

Suter, Paul 2004. Alfurkan Tatarski: Der litauisch-tatarische Koran-Tefsir. Köln-Weimar-Wien: Bölau Verlag.

_ 2009. Alfurkan tatarski: Karan-Tefsir Wialikaha Kniastwa Litouskaha. Tłum. Iryna Synkowa [\&] Wiktar Swiakła [\&] Michaś Tarełka. Red. Hienadź Cychun. Minsk: Technałohija.

Synkowa, Iryna 2016. „Kamientar na sury 78-114 u rukapisach tatarau byłoha WKŁ i jaho suadnosiny z tatarskim pierakładam Karana na polskuju mowu”. W: Monika Krajewska [\&] Joanna Kulwicka-Kamińska [\&] Arleta Szulc (red.). Święte księgi judaizmu, chrześcijaństwa i islamu w stowiańskim kręgu kulturowym: Prace dedykowane Profesorowi Czestawowi Łapiczowi. T. 1: Księgi wyznawców islamu. Kitabistyka. Toruń: Wydawnictwo Naukowe Uniwersytetu Mikołaja Kopernika.

Tarełka, Michaił 2006: „Kałafony minskaha tafsira 1098/1686 г., Zdabytki: Dakumientalnyja pomniki na Biełarusi 8: 34-43.

Temczyn, Siergiej Juriewicz 2015. „Polskij pieriewod pierwoj sury Korana po rukopisiam litowskich tatar: priedwaritielnaja tiekstołogiczeskaja ocenka istocznikow XVIII-XX ww." W: Joanna Kulwicka-Kamińska [\&] Czesław Łapicz (red.). Tefsir tatarów Wielkiego Księstwa Litewskiego: teoria i praktyka badawcza. Toruń: Wydział Filologiczny Uniwersytetu Mikołaja Kopernika.

— 2016. „Arabskij «Tanwir al-Miqbas min Tafsir Ibn Abbas» kak istocznik polskogo pieriewoda Korana po rukopisiam litowskich tatar XVII-XX ww.: sura 1 (Al-Fatiha) и 36 (Yā Sīn)”. W: Monika Krajewska [\&] Joanna Kulwicka-Kamińska [\&] Arleta Szulc (red.). Święte księgi judaizmu, chrześcijaństwa i islamu w stowiańskim kręgu kulturowym: Prace dedykowane Profesorowi Czesławowi Łapiczowi. T. 1: Księgi wyznawców islamu. Kitabistyka. Toruń: Wydawnictwo Naukowe Uniwersytetu Mikołaja Kopernika.

Vanagas, Aleksandras (red.) 1989. Lietuiu pavardžiu žodynas. T. 2. Vilnius: Mokslas. 